\title{
DISCUSSÕES ENTRE PROFESSORES SOBRE A NATUREZA DISCIPLINAR OU INTERDISCIPLINAR DA EDUCAÇÃO AMBIENTAL
}

Everaldo Nunes de Farias Filho ${ }^{1}$

Carmen Roselaine de Oliveira Farias ${ }^{2}$

Resumo: Este artigo visou analisar as percepções de professores de uma escola pública de Pernambuco sobre as propostas da Política Nacional de Educação Ambiental (PNEA) e das Diretrizes Curriculares Nacionais para a Educação Ambiental (DCNEA) acerca da inserção da Educação Ambiental (EA) em contextos escolares. Através da técnica do grupo focal, os professores participantes da pesquisa foram estimulados a refletir e expor suas percepções sobre a natureza disciplinar ou interdisciplinar da EA. A partir da análise dos dados, constatou-se que, mesmo apresentando diferentes concepções, a maior parte dos professores pesquisados afirma que a EA deve ser inserida na escola de forma interdisciplinar, através de projetos contínuos. Os professores justificam essa posição pelo fato de a EA abranger conhecimentos de áreas múltiplas do saber. Em contraponto, a minoria dos docentes defende a criação de uma disciplina de EA a fim de garantir seu espaço no currículo escolar.

Palavras-chave: Educação Ambiental. Ensino Fundamental. Políticas de Educação Ambiental.

\section{TEACHER DISCUSSIONS ABOUT THE DISCIPLINARY NATURE OR INTERDISCIPLINARY OF ENVIRONMENTAL EDUCATION}

Abstract: This article aims to analyze the perceptions of teachers of public school in Pernambuco on the proposals of the National Environmental Education Policy (PNEA) and the National Curriculum Guidelines for Environmental Education (DCNEA) concerning the insertion of environmental education (EE) in school settings. Through the focus group technique, the participating teachers in the study were encouraged to think about and explain their views on the disciplinary or interdisciplinary nature of EA. After analyzing the data, it was found that, even with different ideas, most of the teachers surveyed said that EA should be incorporated in school in an interdisciplinary manner, through ongoing projects. This perception is justified by the scope of knowledge of multiple areas and the knowledge necessary for solving environmental problems. In contrast, a minority of teachers advocates the creation of an EA discipline to ensure its space in the school curriculum.

Keywords: Environmental Education. Elementary Education. Environmental Education policies.

\footnotetext{
${ }^{1}$ Mestre em Ensino das Ciências pela Universidade Federal de Pernambuco (UFPE). Professor Efetivo do Instituto Federal de Pernambuco, Barreiros, Pernambuco, Brasil. everaldo_nff@hotmail.com

${ }^{2}$ Doutora em Educação pela Universidade Federal de São Carlos (UFSCar). Professora do Departamento de Biologia e do Programa de Pós-Graduação em Ensino das Ciências da Universidade Federal Rural de Pernambuco, Recife, Pernambuco, Brasil.

crofarias@gmail.com
} 


\section{DISCUSIONES ENTRE LOS MAESTROS SOBRE LA NATURALEZA DISCIPLINARIA O INTERDISCIPLINARIA DE LA EDUCACIÓN AMBIENTAL}

Resumen: En este artículo se pretende analizar la percepción de los profesores de una escuela pública de Pernambuco sobre las propuestas de la Política Nacional de Educación Ambiental (PNEA) y las Directrices Curriculares Nacionales para la Educación Ambiental (DCNEA) acerca de la inclusión de la educación ambiental (EA) en las escuelas. A través de la técnica de grupo focal, se alentó a los profesores participantes en la encuesta para reflejar y explicar sus puntos de vista sobre la naturaleza disciplinaria o interdisciplinaria de EA. A partir del análisis de datos, se encontró que, incluso con ideas diferentes, la mayoría de los profesores encuestados dijo que EA se debe incorporar en la escuela de manera interdisciplinaria, a través de los proyectos continuados. Los profesores justifican esta posición por el hecho de que el EA abarca el conocimiento de múltiples áreas del conocimiento. Por el contrario, una minoría de profesores aboga por la creación de una disciplina EA para asegurar su lugar en el currículo de la escuela.

Palabras-llave: Educación ambiental. Enseñanza fundamental. Políticas de Educación Ambiental.

\section{Introdução}

A noção de ambientalização tem sido utilizada nas ciências sociais e humanas para designar o processo de internalização das questões ambientais em diversos espaços e setores sociais e, entre eles, o da educação (ACSELRAD, 2010). Nesse processo, a Educação Ambiental (EA) constitui efeito e causa da ambientalização social, ao buscar desenvolver valores, habilidades e atitudes individuais e coletivas, em favor do ambiente ecologicamente equilibrado (CARVALHO; TONIOL, 2010).

No Brasil, especialmente na última década, foram desenvolvidas importantes iniciativas de normatização e institucionalização da EA. A partir da Lei Federal nº 9.795/99, que instituiu a Política Nacional de Educação Ambiental (PNEA), seguiu-se um período de crescente inserção desta temática no campo educacional (BRASIL, 1999).

Em 2002, o Decreto $n^{\circ} 4.281$ regulamentou a PNEA e definiu, entre outras questões, a composição e as competências do Órgão Gestor da PNEA, formado pelos Ministérios do Meio Ambiente (MMA) e da Educação (MEC). Uma das suas primeiras tarefas foi a implementação do Comitê Assessor, uma instância de controle social com a função de acompanhar o Órgão Gestor da PNEA no planejamento e avaliação de diretrizes e ações relativas ao processo de implementação da PNEA (BRASIL, 2002)

Esse foi um passo significativo para ações estruturadoras da EA em âmbito federal, decorrendo daí encaminhamentos para a realização da Conferência Infanto-Juvenil pelo Meio Ambiente, a qual se propõe ao fortalecimento das ações de EA nas escolas e comunidades, por meio de debates e deliberações coletivas em temas de cidadania ambiental.

Outro fato relevante foi a criação da Secretaria de Educação Continuada, Alfabetização, Diversidade e Inclusão (Secadi) e a inserção da Coordenação Geral de Educação Ambiental (CGEA) nessa secretaria, que contribuiu para sua atuação junto às redes estaduais e municipais de ensino. Atualmente, no MEC, são mantidas ações de formação continuada de professores da educação básica, bem como estimulados projetos por meio do Programa Vamos Cuidar do Brasil com as Escolas.

No âmbito das políticas curriculares nacionais, em 2006, a EA foi incluída nas Orientações Curriculares do Ensino Médio e, posteriormente, foram aprovadas as Diretrizes 
Curriculares Nacionais de Educação Ambiental para todos os níveis de ensino, por meio do Parecer CNE/CP n ${ }^{\circ}$ 14/2012, aprovado em 6 de junho de 2012, e da Resolução CNE/CP n ${ }^{\circ}$ 02, de 15 de Junho de 2012 (BRASIL, 2012a). Entre as orientações contidas nesses documentos está a proposta de inserção da EA em contextos escolares numa abordagem interdisciplinar, desencorajando as instituições de ensino a criarem uma disciplina específica de EA.

Nessa esteira, o processo de ambientalização do currículo tem sido o escopo de diversas pesquisas, que visam compreender as formas segundo as quais aEA se insere no contexto da escola (BOTON et. al. 2010; LIMA; FERREIRA, 2010; LIMA; LOPES, 2010; SILVA; DURANS; FARIAS, 2012). Em comum, essas pesquisas indicam os conflitos e desafios que caracterizam os processos de inserção da EA em currículos de diferentes níveis de ensino, geralmente decorrentes dos diferentes sentidos atribuídos à escola, ao processo educativo e às questões ambientais.

Para se avançar na compreensão do fenômeno da ambientalização curricular dentro das instituições de ensino, é importante compreender de que modo os professores recontextualizam as propostas dos textos de políticas educacionais de EA para a construção do currículo escolar. Os professores, nessa perspectiva, não são meros aplicadores das propostas e políticas educacionais, mas são, principalmente, seus intérpretes, e por meio de suas decisões e ações dão contornos ao currículo escolar.

Nesse sentido, o ciclo contínuo de produção de políticas desenvolvido por Stephen Ball, Bowe e Gold (1992) oferece uma base teórica consistente para nossa perspectiva de pesquisa. Segundo essa abordagem, não há separação total entre as instâncias de formulação e de implementação do currículo, visto que as políticas são produzidas em múltiplos contextos que se articulam entre si. Nesses contextos, são múltiplos os produtores de textos e discursos nas políticas curriculares com poderes assimétricos, assim como também o são os sentidos e significados em disputa (LIMA; LOPES, 2010).

De acordo com Mainardes (2006, p.95), essa abordagem destaca "a natureza complexa e controversa da política educacional, enfatiza os processos micropolíticos e a ação dos profissionais que lidam com as políticas no nível local e indica a necessidade de se articularem os processos macro e micro na análise de políticas educacionais". Isso envolve analisar, por um lado, os discursos que atuam na formulação da política e, por outro, a interpretação que fazem deles os profissionais que atuam no contexto da prática.

O ciclo contínuo de produção da política educacional é constituído por três contextos principais: o contexto de influência, o contexto da produção do texto e o contexto da prática. No contexto de influência, os grupos de interesse disputam os sentidos da política, de modo a influenciar a definição das finalidades da educação. Podemos identificar nesse contexto redes, grupos sociais, partidos, governos que atuam no processo legislativo. É nesse âmbito que se formam os principais discursos que informam a produção da política.

Mainardes (2006) informa que o contexto de influência tem uma relação estreita, porém nem sempre evidente, com o contexto da produção do texto. Enquanto o primeiro está, frequentemente, relacionado com interesses mais específicos, os textos políticos estão articulados ao interesse público mais geral. A linguagem empregada nesses textos, contudo, não é necessariamente clara e coerente. Pode haver contradições ou dar margem a diferentes interpretações. Por isso se diz que a produção da política não é concluída no processo legislativo, mas se estende ao contexto da prática, o terceiro contexto.

No contexto da prática, os textos são lidos e reinterpretados conforme as condições subjetivas e objetivas específicas de cada lugar, e estão sujeitos à pluralidade de leituras tantos quantos forem seus leitores. Por meio da interpretação dos profissionais que atuam no contexto da prática, a política é recriada e produz consequências que podem se distanciar dos sentidos originais. Isso porque o leitor interpreta o texto a partir de seu contexto, da sua 
história, experiências, valores e interesses. Uma vez escritos, os significados da política curricular não podem mais ser controlados por quem a escreveu. Essa abordagem sugere que os professores e demais profissionais que atuam na produção do currículo na escola exercem um papel ativo e suas visões têm implicações concretas na deliberação curricular.

Partindo desses pressupostos, esta pesquisa visa compreender como os professores de uma escola pública de Pernambuco reinterpretam as formas de inserção da EA abordadas pelas políticas educacionais, para a construção do currículo, frente à realidade cotidiana da escola.

\section{Educação Ambiental e Interdisciplinaridade}

A década de 1970 foi um período de encontro entre as discussões sobre a interdisciplinaridade e a emergência da EA. No ano de 1970, na cidade de Nice (França) aconteceu o Seminário sobre Interdisciplinaridade e, em 1972, o informe do seminário com o título "Interdisciplinaridade: problemas do ensino e da pesquisa nas universidades" (GONZÁLEZ-GAUDIANO, 2005, p. 122). Naquele mesmo ano, aconteceu a I Conferência Internacional sobre Meio Ambiente, realizada em Estocolmo (Suécia). Passando pelaI Conferência sobre Educação Ambiental em Tbilisi (1977), González-Gaudiano (2005) enfoca que as reuniões internacionais de EA orientam que a dimensão ambiental não deveria ser expressa no currículo na forma de matérias ou cadeiras de ensino. Vejamos a justificativa dada pelo autor:

Temia-se que o manejo nesse aspecto não só fragmentaria o ambiental, como acontece com as demais matérias, como se evitaria a articulação com as diferentes áreas de conhecimento em busca de criar as relações interdisciplinares, que eram consideradas fundamentais para buscar aproximações mais apropriadas à construção de conhecimento e para a aprendizagem do ambiental (GONZÁLEZ-GAUDIANO, 2005, p. 126).

No trecho acima, o autor resgata a preocupação desse contexto de influência sobre as limitações do conhecimento fragmentado em disciplinas na busca de soluções para a crise ambiental, apontando a interdisciplinaridade como proposta para reestruturar o conhecimento, buscando compreender de forma mais holística os problemas da sociedade. Para o autor:

Interdisciplinaridade é um conceito polissêmico, mas em geral costuma ser entendido como uma proposta epistemológica que tende a superar a excessiva especialização disciplinar surgida da racionalidade científica moderna (GONZÁLEZ-GAUDIANO, 2005, p. 123).

Interessante é que, para alguns autores, a discussão sobre a interdisciplinaridade não chega aos diversos contextos em que se processa a produção do currículo de forma verticalizada, ou seja, não partem primeiramente do contexto de influência e chegam ao contexto da prática. De acordo com Pombo, Levy e Guimarães (1994, p.8), a interdisciplinaridade não é uma nova proposta pedagógica, pois não chega à escola de forma exógena ou burocrática, nem com elevado grau de elaboração. Ao contrário, apresenta-se como uma palavra de contornos ainda indefinidos, cuja proposta, aberta, surge dentro das escolas por meio das aspirações de professores que desenvolvem atividades diferentes entre si, tendo em comum o desejo de superar "as barreiras disciplinar a que o ensino está institucionalmente confinado".

De acordo com esses autores, o conceito de interdisciplinaridade está no intervalo entre a concepção de pluridisciplinaridade (justaposição de disciplinas com aproximação de seus campos de conhecimento) e de transdisciplinaridade (rompimento das fronteiras existentes entre as disciplinas): 
Por interdisciplinaridade, deverá então entender-se qualquer forma de combinação entre duas ou mais disciplinas com vista à compreensão de um objeto a partir da confluência de pontos de vista diferentes e tendo como objetivo final a elaboração de uma síntese relativamente ao objeto comum. (POMBO; LEVY; GUIMARÃES, 1994, p. 13).

A relação entre interdisciplinaridade e EA também é discutida por autores como Carvalho (1998, 2008) e Leff $(2000 ; 2006)$. Para Carvalho,

A interdisciplinaridade não pretende a unificação dos saberes, mas deseja a abertura de um espaço de mediação entre conhecimentos e articulação de saberes, na qual as disciplinas estejam em situação de mútua coordenação e cooperação, construindo um marco conceitual e metodológico comum para a compreensão de realidades complexas (CARVALHO, 2008, p. 121).

A conexão entre a questão ambiental e a interdisciplinaridade é estabelecida por Leff (2000), quando relaciona a fragmentação do conhecimento em disciplinas com a alienação das pessoas diante dos problemas ambientais da atualidade. $\mathrm{O}$ autor aponta que deve haver um diálogo entre os diferentes saberes diante da complexidade da problemática ambiental.

A crítica contra a fragmentação do conhecimento em disciplinas também é discutida por Carvalho (1998) quando aponta que a essência da ideia da interdisciplinaridade é ir além das formas de apreender e transformar o mundo, pautadas pela compartimentalização do conhecimento estruturado em disciplinas. Para a autora, a EA deve ser guiada por "uma visão socioambiental" que "orienta-se por uma racionalidade complexa e interdisciplinar" (CARVALHO, 2008, p. 37).

\section{Metodologia}

Este estudo foi realizado com um grupo de onze professores do Ensino Fundamental II (do $6^{\circ}$ ao $9^{\circ}$ ano) de uma escola pública municipal no interior de Pernambuco. Os professores residem no município em que se localiza a escola pesquisada e grande parte leciona também em outras unidades de ensino. Todos os docentes cursaram a graduação em universidades públicas e/ou privadas da região. A maior parte dos professores pesquisados concluiu cursos de Pós-graduação latu sensu em várias áreas da Educação. O Quadro 01 apresenta um perfil profissional dos professores pesquisados:

Quadro 01 - Perfil dos professores participantes

\begin{tabular}{|l|l|l|}
\hline Professor & Formação & Disciplina que leciona \\
\hline Alfa & Geografia & Geografia \\
\hline Beta & Letras & Língua Portuguesa \\
\hline Delta & Letras & Língua Portuguesa/ Ensino Religioso \\
\hline Eta & Letras & Língua Estrangeira (Inglês) \\
\hline Gama & História & História/Geografia \\
\hline Lambda & Letras & Língua Portuguesa/Arte \\
\hline Omega & História & História \\
\hline Omicron & Matemática & Matemática/Ciências \\
\hline Sigma & História & História \\
\hline Tau & Pedagogia & Coordenadora Pedagógica \\
\hline Zeta & Biologia & Ciências \\
\hline
\end{tabular}

O grupo foi estimulado a refletir e expor suas concepções sobre como desenvolver um currículo de educação ambiental na escola a partir, principalmente, da análise de dois 
documentos principais, a Lei Federal $n^{\circ}$ 9.795/99, que institui a Política Nacional de Educação Ambiental (PNEA) (BRASIL, 1999), e a Resolução do Conselho Nacional de Educação n ${ }^{\circ} 02$ de 15 de Junho de 2012, que apresenta as Diretrizes Curriculares Nacionais para a Educação Ambiental (DCNEA) (BRASIL, 2012).

O grupo focal foi empregado como técnica de coleta dos dados, com o objetivo de promover discussões e debates entre os professores sobre a situação investigada. De acordo com Backes et. al (2011) a técnica do grupo focal estabelece-se baseada em uma dimensão dialética, em que a abordagem do tema é realizada pelos participantes auxiliados por um mediador. Segundo Trad (2009, p. 777) "sua adoção atende ao objetivo de apreender percepções, opiniões e sentimentos frente a um tema determinado num ambiente de interação".

O emprego dessa técnica justifica-se por oportunizar um ambiente de diálogo entre os atores envolvidos no processo, de forma que "a marca deste encontro compreensivo é a conversação em que se é interpelado pelo outro" (CARVALHO; GRÜN; AVANZI, 2009). Assim, surgiram os diálogos que foram analisados nesta pesquisa.

As discussões dos professores foram gravadas e transcritas; e, para a análise dos dados, foi feita a seleção das unidades de significados e categorização por convergências de significados. Nas transcrições, para preservar a identidade dos participantes, optamos por substituir os nomes reais dos professores por nomes das letras do alfabeto grego.

\section{Análise dos Dados}

Buscando compreender a maneira pela qual os professores reinterpretam as formas de inserção da EA abordadas pelas políticas educacionais para a construção do currículo frente às realidades do cotidiano da escola, foi lançada a seguinte questão: De que forma a EA deve ser trabalhada na escola? As respostas dos participantes concentraram-se em duas categorias gerais: 1) EA trabalhada na forma de uma disciplina e projetos conjuntamente e 2) EA trabalhada na forma de projetos interdisciplinares.

Quanto à inserção da EA na forma disciplinar, dois docentes justificam sua escolha, alegando que a criação de uma disciplina específica asseguraria o compromisso dos professores em executar práticas ambientais na escola, garantindo a participação de todos os alunos da instituição. Esse argumento assemelha-se ao de Lopez Velasco (2002), para quem é melhor ter a EA como disciplina nos espaços em que houver omissões ou resistências à inserção da EA do que não tê-la em absoluto. Podemos verificar essa posição na fala da professora Tau (coordenadora pedagógica da escola) e da professora Sigma, da área de História:

Professora Tau: Eu acho que deveria ser disciplina. Por que se tornasse uma disciplina então caberia à parte pedagógica fazer projetos pra uma vez no mês todos trabalharem juntos com aquela disciplina. [...] quando tinha as disciplinas moral e cívica, a gente tinha outra postura como pessoa, como profissional [...] Eu penso que assim, trabalhando pelo menos uma vez na semana, essa disciplina ia começar a conscientizar os alunos, dos pequenos aos grandes.

Professora Sigma: Mas eu acredito se vier a se tornar disciplina, não vai ser aquela coisa assim... vai só elaborar um projeto e depois vai pro esquecimento. Você sabendo que tem aquela disciplina, que tem que trabalhar os conteúdos, mas que tem determinados eventos, datas que todo mundo possa trabalhar em conjunto. [...] agora eu pergunto: será o que o projeto alcança todos os alunos? Será que todos participam? Todos participam ativamente? [...] Todos participam ativamente como uma disciplina você trabalhando com o aluno em sala de aula, uma vez por semana, pelo menos. E também: trabalhando com projetos, será que não é uma maneira de se trabalhar como disciplina também? 
As professoras afirmam que a EA inserida na forma de uma disciplina específica do currículo garantiria a conscientização de todos os alunos acerca da questão ambiental, pois, sendo uma disciplina, haveria a obrigatoriedade de se trabalhar os conteúdos da EA semanalmente, além dos eventos em que os docentes poderiam trabalhar juntos.

A professora Sigma ainda questiona a inserção da EA na forma de projetos indagando se os resultados conseguem abarcar todos os alunos. Em sua fala, a professora aponta para um trabalho semanal e disciplinar de EA, em sala de aula, como forma de garantir que as questões ambientais serão inseridas na formação dos alunos.

No entanto, a professora Tau, em seu discurso, não esclarece de quem seria a responsabilidade pela condução da disciplina. No sentido de deixar mais clara essa ideia, pedi à coordenadora que informasse como a mesma poderia ser inserida na escola:

Professora Tau: Como matéria mesmo [...] Então eu acho que deveria, sim, ser como uma disciplina. [...] porque, por exemplo, no começo do ano teve um projeto de Religião. Eu elaborei um projeto de Ensino Religioso. Abrangi, assim, Português, História. Vieram outras disciplinas que eu coloquei. Até pra Páscoa... E eu só vi Artes trabalhando. Então eu acho que tem essa possibilidade, sim, de se tornar uma disciplina.

Mencionando um exemplo de uma prática desenvolvida na disciplina de Ensino Religioso para justificar sua concepção, a coordenadora explica que os projetos multidisciplinares elaborados na escola são executados apenas pelos professores das áreas mais relacionadas ao projeto. Para ela, a inserção da EA na escola se daria pela criação de uma disciplina de EA, na qual os professores executariam projetos criados pela coordenação pedagógica. Diante disso, surgiu a seguinte dúvida: a disciplina de EA seria, então, conduzida pela coordenação pedagógica ou por um professor? A resposta foi dada pela professora Sigma e corroborada pela coordenadora pedagógica. Vejamos o trecho:

Professora Sigma: Com professor capacitado. Mas que todo mundo também tenha um apoio teórico pra, também, trabalhar junto com os alunos, como um suporte na sua disciplina. Mas que tenha ela como disciplina. Se não tiver um professor de frente, cada um vai ficar esperando: "Ah, fulano vai fazer o projeto hoje? É de que tema? Vai fazer o quê?" fica aquela coisa sem compromisso.

Professora Tau: Exatamente. Porque, justamente, fica todo mundo acomodado esperando por alguém. É o meu ponto de vista.

Mostrando-se bastante objetiva em sua resposta, a professora Sigma defende que um único professor deve ministrar a disciplina, porém esse trabalho deverá ser auxiliado pelos demais componentes do corpo docente. As professoras justificam seus argumentos, considerando que, um único professor regente da disciplina seria garantia da eficácia da inserção da EA na escola. Nessa ótica, tendo alguém à frente da disciplina de EA, evitaria o descompromisso, frequentemente apresentado pelos docentes, quando a mesma é desenvolvida na forma de projetos.

A partir das colocações das professoras Sigma e Tau para justificar a inserção da EA em contextos escolares na forma de uma disciplina, verifica-se que elas não consideram viável, pelos motivos apresentados acima, a orientação de inserção da EA de forma interdisciplinar trazida pelos textos da PNEA e das DCNEA. Contudo, percebemos que a defesa das professoras por uma disciplina de EA atenta apenas sua inclusão no currículo escolar, assegurando que ela esteja presente, semanalmente, nos horários fixos das aulas. Com isso, deixam de abordar discussões relevantes da área, como a necessidade de se assegurar de que sejam trabalhadas as inter-relações físicas, biológicas, econômicas, sociais e culturais inerentes à compreensão das questões ambientais (LEFF, 2006). Além disso, essa defesa parece negar a histórica orientação da perspectiva interdisciplinar da EA presente nas 
conferências ambientais, Estocolmo (1972); Belgrado (1975); Tbilisi (1977) (COSTA; LOUREIRO, 2013).

A segunda categoria geral de respostas reúne a visão de um conjunto de seis professores que discordaram sobre a inserção da EA na forma de uma disciplina específica do currículo. Para esses professores, ela deveria ocorrer na forma de projetos.

Professora Alfa: Na época falava assim: por que a interdisciplinaridade? Para que o conteúdo ele não fosse fragmentado. Então se a EA se tornasse uma disciplina, ela se torna aquela coisa específica e se ela (EA) é um tema transversal, perpassa em todas as áreas do conhecimento. Então qual seria esse profissional pra ter um amplo conhecimento a ponto de desenvolver EA na escola de forma precisa? A educação ambiental ela tem que ser um projeto, mas só que esse projeto tem que ser um projeto permanente, contínuo. Educação ambiental é um processo contínuo.

Professora Gama: Se vier a se tornar disciplina, vai ser algo conteudista. Vai se trabalhar mais conteúdo do que o próprio ambiente, do que a própria formação. Se vier a se tornar disciplina.

Professora Beta: Eu penso que não deveria ter um professor específico e eu penso que não deveria ser disciplina em hipótese alguma. [...] jamais um professor. "Uma andorinha só não faz verão". Tem que ser todas as áreas trabalhando ao mesmo tempo.

Ao apontar a inserção da EA na escola, na forma de projetos, alguns professores justificam suas ideias, afirmando que a EA deve perpassar todas as áreas do conhecimento, pois possui natureza interdisciplinar. Tal visão encontra fundamento nos estudos realizados por Leff (2000, 2006), Carvalho (1998, 2008) e González-Gaudiano (2005), que discutem a natureza interdisciplinar da EA, baseando-se na complexidade da problemática ambiental.

Uma crítica à inserção da EA na forma de uma disciplina é feita pela professora Gama. Em sua fala, a professora afirma que uma disciplina de EA priorizaria o foco nos conteúdos da área ambiental. Contudo, ela sinaliza que esse tipo de abordagem negligenciaria o enfoque no processo de formação do aluno no campo ambiental. Isso nos remete a uma visão críticotransformadora da EA, que reconhece a importância da ênfase no processo de formação. Nessa visão, um dos desafios da área da EA escolar é a valorização da formação numa perspectiva em que o aluno atue em sua realidade de forma crítica, não neutra e transformadora (TORRES, FERRARI; MAESTRELLI, 2014).

Outro argumento, usado por esses professores para defender a inserção da EA por meio de projetos, é a inexistência de um professor capaz de responder pelo conjunto de conhecimentos que compõe a EA. Segundo eles, um único professor não teria a formação suficiente para abranger todos os temas referentes à questão ambiental de forma aprofundada, devido às especificidades das áreas de formação inicial. Vejamos o excertoem que foi realizado o seguinte questionamento: Porque vocês acham que a EA não deve ser ministrada por um único professor?

Professora Alfa: Porque vai de acordo com a formação dele. Veja, a gente tem um conhecimento, mas a gente sempre foca a formação da gente. Na área de Educação, como professor, a minha formação é Geografia. Uma coisa que eu não gosto e já aconteceu: "Alfa, você vai ensinar História". Bem, a gente se esforça, mas a gente ensina de forma superficial. Tá entendendo? Quem perde são os alunos, minha gente.

Professora Zeta: Tem o técnico. Tem especialização, Gestão ambiental.

Professora Alfa: Que é diferente.

Professora Tau: Independente do que eu tenha me formado, se eu posso contribuir de alguma forma, então eu tenho que buscar mesmo. Então eu acho que cada um tem, sim, capacidade, sim, de ir mais além, mesmo que não seja sua área. Então eu acho que deveria ser sim, disciplina, mesmo que não tivesse uma formação pra atuar. Especialização a gente sabe que já tem, mas, eu acho que, se o professor é da área ou não ele pode contribuir. Do mesmo jeito que o professor de História dá aulas 
de Geografia, porque ele não pode contribuir com EA, se envolve também um pouco de Geografia, se envolve também um pouco de História, Ciências, enfim?

Contudo, essa ideia de que a EA não poderia ser trabalhada na forma de disciplina pelo fato de não haver professor com formação inicial em EA foi contestada pelos que defendem a EA disciplinar. O contra-argumento baseou-se, principalmente, na existência de cursos de Pós-Graduação lato sensu na área de EA que poderiam sanar essa carência da formação inicial. Diante isso, indagamos: que professor estaria mais apto a ministrar a disciplina de EA? Alguns docentes citaram professores de Ciências e Geografia. No entanto, grande parte defendeu que os professores dessas disciplinas necessitariam do conhecimento de outras áreas para dar conta do trabalho com EA, como podemos ver no trecho a seguir:

Professora Alfa: O de Ciências.

Professora Lambda: Ciências.

Professora Alfa: Saíram outras questões ali (cidadania, ética, consumismo), mas, no geral, seria o de Ciências, ou em segundo ponto, Geografia.

Professora Lambda: Ou nas escolas que tivessem pessoas, tipo você (pesquisador), aprendizagem nisso.

Professora Omicron: Geografia.

Professora Alfa: Não seria EA.

Professora Gama: Não seria.

Professora Alfa: Por que o que é educar? Educar é saber lidar com o Meio Ambiente, que o Meio Ambiente não é só natureza, agente precisa pensar aí na parte social.

Professora Gama: Não é algo distante. O ambiente é onde estamos.

Professora Alfa: Estamos nele.

Pesquisador: Do que vocês colocaram, vocês acreditam que o professor de Biologia dá conta?

Professora Alfa: Não.

Professora Eta: Ele vai precisar, por isso que é interdisciplinar. Ele vai precisar de outras. Vai precisar de Geografia, vai precisar de... Citaram só Biologia. Não, citou Geografia, Português...

Professora Gama: História

Professora Eta: História. Porque ele vai ter que saber alguma coisa de História que tá ali, alguma coisa da área de História. Inglês é um pouco mais difícil.

Professora Alfa: Justamente, olha aí. Cadê o professor de EA?

Por meio da análise dessas discussões, constatei uma luta pela hegemonia sobre a melhor maneira de inserção da EA na escola. Os professores, procurando defender seus pontos de vista, transformam o debate numa verdadeira arena em que emergem conflitos de concepções, como é evidenciado nos estudos de Lopes (2004) e Macedo (2006) e Lopes e Macedo (2011) durante a construção do currículo em EA. Em meio a discussões e debates sobre qual a melhor forma de se inserir a EA, a maioria dos professores decidiu optar por trabalhá-la na forma de projetos interdisciplinares pautados numa visão socioambiental. Tal decisão é mostrada no diálogo abaixo:

Professora Sigma: Se a EA não pode ser trabalhada como disciplina, então como ela pode ser trabalhada?

Professora Beta: De forma interdisciplinar.

Professora Sigma: Como? Como?

Professora Alfa: De projetos

Professora Beta: De projetos

Professora Eta: De projetos

Professora Delta: De projetos.

Professora Sigma: Só com projetos?

Professora Eta: Não. O projeto é anual, de forma contínua.

Professora Beta: Anual

Professora Alfa: Anual 
Professora Zeta: Isso é lei. E diz que cada disciplina deve trabalhar EA, com objetivos.

O diálogo apresenta a posição da maioria dos professores em inserir a EA na escola por meio de projetos interdisciplinares e contínuos. No entanto, constatei que os mesmos professores que optaram por essa forma de inserção apontam algumas dificuldades de se trabalhar a EA de forma interdisciplinar. O primeiro obstáculo se refere ao fato de a escola e seus agentes não se enquadrarem em um formato interdisciplinar, como é evidenciado na fala das professoras Alfa e Delta:

Professora Alfa: A grande dificuldade é que a nossa escola não está no formato de interdisciplinaridade. Nós trabalhamos isoladamente, nós trabalhamos assim, por área. A culpa não é nossa não, é porque a gente não tem essa formação lá na base. Nós não temos, chegou pra gente depois. Se a gente pega a época da graduação da gente não tá na nossa prática de formação. Então é difícil.

Professora Delta: Eu coloquei também formação. [...] porque a partir daí, se tiver estabelecido esse debate aqui com os professores, essa discussão e um planejamento e um projeto articulado, ele acontece.

Percebe-se que a professora Alfa dá ênfase à deficiência em EA na formação inicial dos professores. Por sua vez, essa carência leva à formação de profissionais que desconhecem a problemática ambiental e sua perspectiva socioambiental e interdisciplinar. Esse argumento é, também, evidenciado nos estudos de Severino (1989). O autor afirma que os currículos de vários cursos de formação de profissionais não garantem uma metodologia fundamentada nos princípios da interdisciplinaridade.

Dessa forma, o desenvolvimento de abordagens teórico-metodológicas que garantam o desenvolvimento de atributos da EA numa perspectiva interdisciplinar apresenta-se, como já citado, como outro desafio lançado à área da EA escolar (TORRES; FERRARI; MAESTRELLI, 2014). Isso pode se tornar contraditório à primeira vista, uma vez que a EA já conta com mais de quarenta anos de processos que a vem institucionalizando na esfera educativa. Contudo, essa lacuna no processo de formação inicial pode ser entendida pelo fato de que a EA só passou a fazer parte, de forma efetiva, de contextos escolares a partir dos anos finais da década de 1990, com a criação dos Parâmetros Curriculares Nacionais e da implementação da PNEA.

No sentido de complementar o discurso da professora Alfa, a professora Delta aponta como dificuldade a falta de formação em EA para os professores em exercício. Para ela, a criação de ambientes que proporcionem discussões acerca da questão ambiental com a internalização da problemática ambiental é essencial para a obtenção de bons resultados nos projetos de EA desenvolvidos na escola. Diante das dificuldades apresentadas pelas professoras supracitadas, observei que suas reivindicações estão explícitas na PNEA e nas DCNEA, as quais tratam, respectivamente, da obrigatoriedade da inserção da EA na formação inicial dos professores e na formação complementar para os professores que estiverem em exercício. A última dificuldade apresentada é relatada pela professora Omega:

Professora Omega: O professor não tem espaço. Qual é o espaço que o professor tem? O que se preocupa com educação hoje em dia é só sala de aula. Pensa que um momento desse não tá sendo proveitoso. Isso aqui é um momento muito enriquecedor pra todos nós. O governo não está se preocupando em criar cidadãos inteligentes e que tem cultura. Ele tá se preocupando em criar cidadãos que saibam ler e escrever e fique só assim sem olhar pra outros ângulos.

Em seu discurso, a professora Omega aponta a falta de espaço para planejamento e desenvolvimento de ações em EA como empecilho para inseri-la em suas práticas escolares. Ela alega ter que utilizar todo tempo disponível com atividades em sala de aula. Para Omega, a omissão de espaços para que os professores possam deliberar de forma interdisciplinar as 
práticas educativas em EA limita a reflexão e, consequentemente, a oportunidade de se criar condições para que os alunos discutam, criticamente, sobre questões ambientais.

Durante a realização da pesquisa, apenas dois, dos onze professores pesquisados, afirmaram que já conheciam o texto da PNEA. Contudo, nenhum dos docentes afirmou ter conhecimento do texto das DCNEA. Apesar desses documentos de EA não fazerem parte do cotidiano dos professores, verificamos que as ideias desses textos permeiam seus espaços de trabalho e influenciam suas concepções.

\section{Considerações Finais}

Após a análise dos dados, verifiquei que seis dos onze professores pesquisados afirmam que a EA deve ser inserida na escola por meio de projetos interdisciplinares e contínuos. Tal escolha é justificada pelos seguintes argumentos: a) a EA é interdisciplinar e, portanto, transversal, logo deve permear todas as disciplinas; b) para ser disciplinar deve haver um professor específico de EA, porém não existe um docente com formação específica em EA e que possa conduzir, sozinho, essa possível disciplina; c) a EA abrange conhecimentos de áreas múltiplas do saber.

Os professores explicitaram que a inserção da EA numa perspectiva interdisciplinar deve ocorrer na forma de projetos contínuos, os quais abordariam temas que refletem os problemas ambientais locais. Todavia, constatei que alguns dos professores que optaram por inserir a EA de forma interdisciplinar apontam algumas dificuldades para se trabalhar dentro dessa perspectiva: a) os docentes não receberam formação para trabalhar de maneira interdisciplinar na sua graduação; b) a escola não está estruturada para realizar atividades interdisciplinares; c) não é disponibilizado espaço para planejamento e avaliação de práticas interdisciplinares dentro da escola.

Contudo, dois dos docentes pesquisados defenderam que a EA pode e deve ser trabalhada como uma disciplina do currículo escolar. Essa disciplina ficaria sob a responsabilidade de um professor específico, que se encarregaria de trabalhar com os alunos, em sala de aula, os projetos desenvolvidos pela equipe pedagógica da escola. Os professores justificaram sua preferência, argumentando que a EA como disciplina reforça o compromisso que eles terão em abordá-la semanalmente. Além disso, afirmam que o trabalho com EA na forma de projetos torna-se vago e não atinge todos os alunos da escola.

Os resultados dessa pesquisa permitem compreender um pouco sobre a influência das políticas educacionais de EA no cotidiano da escola e, em particular, as interpretações dos professores sobre os direcionamentos trazidos por essas políticas acerca da inserção da EA em contextos escolares.

Considero que ainda existe muito a ser pesquisado sobre esse tema dentro das escolas. Contudo, os resultados deste estudo configuram-se como elementos que vêm ampliar a compreensão sobre esse fenômeno, assim como contribuir para repensar tais políticas.

\section{Referências}

ACSELRAD, H. Ambientalização das lutas sociais - o caso do movimento por justiça ambiental. Estud. av., São Paulo, v.24, n.68, p. 103-119, Jan/Mar. 2010.

BACKES, D. S. et al. Grupo focal como técnica de coleta e análise de dados em pesquisas qualitativas. O Mundo da Saúde, São Paulo, v. 35, n. 4, p. 438-442, Out./Dez. 2011. 
BOWE, R.; BALL, S. J. \& GOLD, A. Reforming education \& changing school: case studies in policy sociology. London - New York: Routlegde, 1992.

BOtON, J. M; COSTA, R. G. A.; KURZMANN, S. M.; TERRAZZAN, E. A. O meio ambiente como conformação curricular na formação docente. Revista Ensaio, Belo Horizonte, v.12, n.3, p. 41-50, Set/Dez. 2010.

BRASIL. Lei Federal $n^{o}$. 9.795, de 27 de abril de 1999. [Online]. Dispõe sobre a educação ambiental, institui a Política Nacional de Educação Ambiental e dá outras providências. Brasília: Casa $\quad$ Civil, $1999 . \quad$ Disponível em: <http://www.planalto.gov.br/ccivil_03/leis/19795.htm>. Acesso em: 20 nov. 2015.

BRASIL. Decreto n ${ }^{\circ} 4.281$, de 25 de Junho de 2002. Regulamenta a Lei no 9.795, de 27 de abril de 1999, que institui a política nacional de educação ambiental, e dá outras providências. Diário Oficial da República Federativa do Brasil, Brasília, DF, 26 de junho de 2002. Seção 1, p. 13.

BRASIL, Ministério da Educação. Conselho Nacional de Educação/Conselho Pleno. DF. Parecer CNE/CP No 14, de 6 de Junho de 2012. Propõe o estabelecimento de Diretrizes Curriculares Nacionais para a Educação Ambiental. Diário Oficial da República Federativa do Brasil, Brasília, DF, 15 de junho de 2012. Seção 1, p. 18.

BRASIL. Conselho Nacional de Educação. Resolução n. 2, de 15 de Junho de 2012. Estabelece as Diretrizes Curriculares Nacionais para a Educação Ambiental. Diário Oficial da República Federativa do Brasil, Brasília, 18 de junho de 2012. Seção 1, p. 70.

CARVALHO, I. C. de M. Em direção ao mundo da vida: interdisciplinaridade e educação ambiental. Cadernos de Educação Ambiental, Brasília, v. 2, s/n., p.1-37, 1998.

CARVALHO, I. C. de M. Educação ambiental: a formação do sujeito ecológico. 4ed. São Paulo: Cortez, 2008.

CARVALHO, I. C. de M; GRÜN, M., AVANZI, M. R. Paisagens da compreensão: contribuições da hermenêutica e da fenomenologia para uma epistemologia da educação ambiental. Cad. Cedes, Campinas, v. 29, n. 77, p. 99-115, Jan/Abr. 2009.

CARVALHO, I. C. de M.; TONIOL, R. F. Ambientalização, cultura e educação: diálogos, traduções e inteligibilidades possíveis desde um estudo antropológico da educação ambiental. Revista Eletrônica do Mestrado em Educação Ambiental, Rio Grande, v. Esp., p.1-12, Set. 2010.

COSTA, C. A. S.; LOUREIRO, C. F. B. Educação ambiental crítica e interdisciplinaridade: a contribuição da dialética materialista na determinação conceitual. Revista Terceiro Incluído, Goiânia, v.3, n13, p. 1-22, Jan/Jun. 2013.

GONZÁLEZ-GAUDIANO. E. Interdisciplinaridade e educação ambiental: explorando novos territórios epistêmicos. In: SATO, M.; CARVALHO, I. (Orgs.). Educação ambiental: pesquisa e desafios. Porto Alegre: Artmed, 2005, p. 121-135. 
LEFF, E. Complexidade, interdisciplinaridade e saber ambiental. In: PHILIPPI JR., A. (Org.) Interdisciplinaridade em Ciências Ambientais. São Paulo: Signus, 2000. p. 19-50.

LEFF, E. Racionalidade ambiental: a reapropriação social da natureza. Tradução de Luís Carlos Cabral. Rio de Janeiro: Civilização Brasileira, 2006.

LIMA, M. J. G. S.; LOPES, A. R. C. A disciplina da educação ambiental na política curricular da rede municipal de Armação dos Búzios (RJ). Revista e-curriculum, São Paulo, v.6, n.2, p. 1-19, Dez. 2010.

LIMA, M. J. G. S.; FERREIRA, M. S. Educação Ambiental na escola: investigando sentidos sobre interdisciplinaridade e disciplinarização nas políticas de currículo. In: Curso de formação de educadores ambientais: a experiência do Projeto Pólen. Macaé: NUPEM/UFRJ, 2010. p. 227-247.

LOPES, A. C. Políticas curriculares: continuidade ou mudança de rumos? Revista Brasileira de Educação, Campinas, v. 9, n. 26, p. 109-118, Mai./Ago.2004.

LOPES, A.C.; MACEDO, E. Teorias de currículo. São Paulo: Cortez, 2011.

LOPEZ VELASCO, S. Algumas reflexões sobre a PNEA [Política Nacional de Educação Ambiental, Lei № 9.795 de 27/04/1999]. Revista Eletrônica do Mestrado em Educação Ambiental, Rio Grande, v. 8, n.1, p. 12-20, Jan./Jun. 2002.

MACEDO, E. Currículo: Política, Cultura e Poder. Currículos sem Fronteiras, Rio de Janeiro, v. 6, n. 2, p. 98-113, Jul/Dez. 2006.

MAINARDES, J. A abordagem do ciclo de políticas e suas contribuições para a análise da trajetória de políticas educacionais. Atos de Pesquisa em Educação, Blumenau, v.1. n. 2, p. 94-105, Mai./Ago. 2006.

POMBO, O.; LEVY, T.; GUIMARÃES, H. A interdisciplinaridade: reflexão e experiência. 2.ed. Lisboa

SEVERINO, A. J. Subsídios para uma reflexão sobre novos caminhos da interdisciplinaridade. In: SÁ, J. L. M. (Org.) Serviço social e interdisciplinaridade: dos fundamentos filosóficos à prática interdisciplinar no ensino, pesquisa e extensão. São Paulo: Cortez, 1989. p. 11-21.

SILVA, R. P.; DURANS, T. S.; FARIAS, C. R. O. Ambientalização curricular - o caso da disciplina de Educação Ambiental na política curricular de Pernambuco. In: COLÓQUIO INTERNACIONAL EDUCAÇÃO E CONTEMPORANEIDADE, 6, São Cristóvão, 2012. Anais... São Cristóvão: EDUCON, 2012. p.1-12. Disponível em: <http://educonse.com.br/2012/eixo_17/PDF/43.pdf> Acesso em: 19 Fev. 2014.

TRAD, L. A. B. Grupos focais: conceitos, procedimentos e reflexões baseadas em experiências com o uso da técnica em pesquisas de saúde. Physis Revista de Saúde Coletiva, Rio de Janeiro, v. 19, n.3, p. 777-796, Jul/Set. 2009. 
TORRES, J. R.; FERRARI, N.; MAESTRELLI, S. R P. Educação ambiental críticotransformadora: teoria e prática freiriana. In: LOUREIRO, C. F. B.; TORRES, J. R. (Orgs.). Educação ambiental dialogando com Paulo Freire. São Paulo: Cortez, 2014. p. 13-80.

Versão recebida em 16/12/2014

Aceite em 26/08/2015 